\title{
Propolis influence on erythrocyte membrane disorder (hereditary spherocytosis): A first approach
}

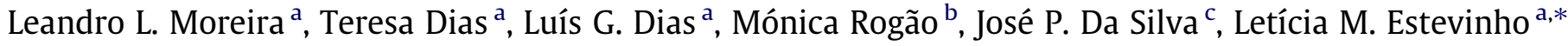 \\ ${ }^{a}$ CIMO - Escola Superior Agrária, School of Agriculture, Instituto Politécnico de Braganca, Campus Santa Apolónia, Apartado 1172, 5301-855 Braganca, Portugal \\ ${ }^{\mathrm{b}}$ Escola Superior de Saúde de Bragança, School of Health, Instituto Politécnico de Braganca, Avenida D. Afonso V, 5300-121 Bragança, Portugal \\ 'Faculdade de Ciências e Tecnologia, Universidade do Algarve, Campus de Gambelas, 8005-139 Faro, Portugal
}

\section{A R T I C L E I N F O}

\section{Article history:}

Received 5 October 2010

Accepted 29 November 2010

\section{Keywords:}

Bee product

Phenolic compounds

Erythrocyte membrane

Apis mellifera

\begin{abstract}
A B S T R A C T
Propolis is a resinous substance collected from plants by bees. Its composition depends on the vegetation, the season, and the source area. It usually contains many chemical compounds such as polyphenols, steroids and amino acids.

The hereditary spherocytosis (HS) is a type of anaemia characterized by microcytic and hyperchromic red cells, spherical in shape and without central pallor. Clinically, subjects present from asymptomatic conditions to severe haemolytic anaemia.

In this study it was evaluated the effect of two propolis extracts in the osmotic fragility of HS patient red blood cell ( $\mathrm{RBC}$ ) membrane. It was found that propolis decreases the erythrocytes membrane fragility, being the effect of Bornes propolis more pronounced than Fundão propolis'. This effect was related with the higher phenolic content of the former propolis. The results obtained in vitro suggest that the membrane fragility increases under oxidative stress conditions for the patient RBC's and the protection effect of propolis is due to its antioxidant properties. These results open doors for future investigations in order to elucidate the mechanisms, identify the main compounds involved in this fragility protection of the erythrocyte membrane. This is the first work reporting an evaluation of the propolis effect in a blood disease.
\end{abstract}

(c) 2010 Elsevier Ltd. All rights reserved.

\section{Introduction}

The hereditary spherocytosis (HS) is a congenital haemolytic anaemia that increases the susceptibility to haemolysis and decreases the cell life expectancy. HS is the most common red blood cell (RBC) membrane disorder in European Caucasians. Its prevalence is roughly $200-300$ per $10^{6}$, while for Japanese population, for example, the frequency is 5.7-20.3 per $10^{6}$, (Satchwell et al., 2009; Orcutt et al., 1995; Granjo et al., 2003).

HS is caused by a defect in the erythrocyte membrane that leads to instability of the cell cytoskeleton (Favero et al., 2003). The cells acquire a smaller spherical shape and are quickly kidnapped by the movement of the spleen, which leads to an increase in the erythrocytes production by bone marrow.

Recent studies suggest that HS can be caused by deficiency in four different erythrocyte membrane proteins: (1) spectrin; (2) anquirin associated spectrin; (3) band 3; (4) protein 4.2, being

\footnotetext{
* Corresponding author. Tel.: +351 273 303275; fax: +351273 325405 .

E-mail address: leticia@ipb.pt (L.M. Estevinho).
}

the deficiency in spectrin the most common (Granjo et al., 2003; Rocha et al., 2009).

The oxidative damage of erythrocytes membranes associated with HS is similar to the observed for other haemolytic anaemia and has been associated with the pathological pathway of this disease (Margetis et al., 2007). Previous studies established that oxidation of membrane proteins leads to red cell vesiculation (Wagner et al., 1986). HS patients show higher haemoglobin and high molecular weight hb-immunopositive contents in their RBC membranes (Margetis et al., 2007). This membrane bound-oxidized haemoglobin induces clustering of band 3 on the membrane surface. This aggregation leads to autologous IgGs and complement binding and consequently to erythrophagocytosis.

The identification of microspherocytes in blood film is a very easy and quick procedure for a diagnosis of HS. Additionally, the diagnosis may also be done by the osmotic fragility test. This test measures the in vitro lysis of RBCs suspended in solutions of decreasing osmolarity (Tracy and Rice, 2008).

Propolis (bee glue) is a beehive product prepared by bees of the Apis mellifera species, using resinous substances collected from various plants. These substances are mixed with $\beta$-glycosidase 
enzyme of their saliva, partially digested, and added to bee wax to form the final product. Bees use it to seal holes on the beehive walls, and to protect themselves against invaders by wrapping them with propolis. The invaders die by asphyxia and their bodies are preserved, which prevents the putrefaction of the honeycomb (Salatino et al., 2005).

As a natural substance, it has been used since the primordial times by ancient civilizations such as Egyptians, Arabs, Greeks, and many others, particularly in folk medicine, due to its therapeutic properties (Bankova, 2005). Nowadays, there is an increasing interest on beehive products, particularly in propolis, mostly because of its applications in health care, cosmetics and food addictive production (Daugsch et al., 2008). The health care applications of propolis are a particularly important area. This natural substance shows different biological actions, namely anti-inflammatory (Moura et al., 2009), antibacterial (Salomão et al., 2008), antifungal (Moura et al., 2009), anti-viral (Amoros et al., 1994), curative, anaesthetic, anti-tumour (Szliszka et al., 2009; Búfalo et al., 2009) and has also antioxidant properties (Moreira et al., 2008). It is therefore expected to be very efficient for wound healing, tissue regeneration, treatment of burns, psoriasis, herpes simplex and genitalis, rheumatism, sprains, dental medicine and immune system support and improvement (Moura et al., 2009). The potential use of propolis lead to an increased interest in new applications and in its chemical composition. However, propolis is a very complex mixture. More than 300 constituents have been identified in different types of propolis (Bankova et al., 2000). Polyphenolic compounds are the most abundant, suggesting that these chemicals are correlated to the bioactive properties of propolis. Furthermore, propolis chemical composition and concentration of biologically active substances depends on the geographic localization of the plants that the bees feed on (Marcucci, 1995; Bankova et al., 2000; Marcucci and Bankova, 1999; Park et al., 2002; Moreira et al., 2008). So, a characterization of propolis in terms of its content and type of bioactive components is particularly important to its standardization, a condition for the official acceptation of this natural product in the main stream of health care system.

The main goal of this work is to evaluate the effect of propolis from two different origins in the osmotic fragility of RBC from patients with HS, with and without oxidation stress conditions. This is the first study about the action of Portuguese propolis in haematological diseases. The results and the information provided are the basis for future investigations, namely elucidation of the mechanisms of propolis action on the fragility of the erythrocyte membrane.

\section{Materials and methods}

\subsection{Sample preparation and analysis}

Propolis from two Portuguese regions: Bornes - Trás-os-Montes and Fundão Beira Interior, were used. The samples were prepared by mixing propolis with methanol $(1: 1 \mathrm{v} / \mathrm{v})$ and letting under stirring over-night. The obtained solution was then filtered (Whatman no. 4) to remove the solid particles. The eluate was then extracted twice with methanol, as described earlier (Moreira et al., 2008). The combined methanolic extracts were frozen at $-20^{\circ} \mathrm{C}$ during $12 \mathrm{~h}$ and then filtered to remove wax particles. Finally the methanol was evaporated using a rotary evaporator, and the extracts re-dissolved in DMSO (20\%).

The purified propolis samples were analysed by LC-MS to compare the polyphenol profile differences between the two used propolis materials. The two propolis materials were dissolved in methanol $(\sim 10 \mathrm{mg} / 25 \mathrm{~mL})$ and injected without any other processing step. The LC-MS system is an Agilent Technologies 1200 Series LC coupled to a Bruker Daltonics HCT ultra (ion trap detector). The ionization was made by electro-spray (ESI) in the negative and positive polarities. Typical ESI conditions were nebulizer pressure $50 \mathrm{psi}$, capillary voltage $3.0 \mathrm{kV}$ and drying gas temperature $300^{\circ} \mathrm{C}$. A Purospher STAR (Merck) LiChroCART 125-2 (12.5 cm length, $2 \mathrm{~mm}$ internal diameter, RP-18, $5 \mu \mathrm{m}$ ) column stabilized at $30^{\circ} \mathrm{C}$ was used. The flow was $0.4 \mathrm{~mL} / \mathrm{min}$. The composition of the mobile phase was similar to the reported previously (Falcão et al., 2010). The fragmentation spectra (MS ${ }^{2}$ ) were obtained using Auto MS( $n$ ); higher order fragmentations were made by direct infusion into the mass spectrometer.

\subsection{Patient}

The patient, a 22-years-old male from North Portugal, was born healthy, with non-consanguineous parents and no known family history of anaemia. His clinical history includes: an intravascular haemolysis that required hospitalization at the age of 9-months; diagnosis of hereditary spherocytosis at the age of 12-months; severe anaemia $(4.2 \mathrm{~g} / \mathrm{dL})$ that required two erythrocytes transfusion at the age of 18 -months; splenectomy and removal of the gallbladder at the age of 2-years. Since then the patient takes oral penicillin twice a day and had a normal health and development.

\subsection{Peripheral blood smear and Wright's stain}

Peripheral blood smear was stained with Wright's stain and analysed under an optical microscope $(1000 \times)$.

\subsection{Preparation of saline solutions}

The saline solutions were prepared using a stock solution containing $100 \mathrm{~g}$ of $\mathrm{NaCl}, 13.65 \mathrm{~g}$ of $\mathrm{Na}_{2} \mathrm{HPO}_{4}, 2.34 \mathrm{~g}$ of $\mathrm{NaH}_{2} \mathrm{PO}_{4} \cdot 2 \mathrm{H}_{2} \mathrm{O}$, in one litre of deionized water. The following concentrations $(\mathrm{g} / \mathrm{L})$ were prepared: $0.0 ; 1.0 ; 2.0 ; 3.0 ; 3.5 ; 4.0 ; 4.5$; $5.0 ; 5.5 ; 6.0 ; 6.5 ; 7.0 ; 8.0 ; 9.0 ; 10.0$

\subsection{RBC membrane integrity evaluation - osmotic fragility test (OFT)}

\subsubsection{Propolis influence on OFT}

Samples of the heparinised blood of the patient and of the blood of a healthy individual (control) were used. Consent was obtained from both individuals. The test was done within the recommended interval of $2 \mathrm{~h}$ after collection, at room temperature.

The heparinised blood was exposed to propolis DMSO extracts $(10 \mu \mathrm{g} / \mathrm{mL})$ during $10 \mathrm{~min}$ and was then washed twice using a physiological saline solution. After this step, $50 \mu \mathrm{L}$ of RBCs were added to a series of tubes containing $5 \mathrm{~mL}$ of sodium chloride at different concentrations and incubated at room temperature for $30 \mathrm{~min}$. The tubes were carefully shacked and the haemolysis was quantified at $540 \mathrm{~nm}$, using the solution containing $10.0 \mathrm{~g} / \mathrm{L} \mathrm{NaCl}$ as blank. The haemolysis percentage was calculated using the solution with $0.0 \mathrm{~g} / \mathrm{L} \mathrm{NaCl}$ as $100 \%$ of haemolysis. The degree of haemolysis was related with the concentration of saline solution and the results are presented graphically.

\subsubsection{Effect of hydrogen peroxide $\left(\mathrm{H}_{2} \mathrm{O}_{2}\right)$ in OFT}

The procedure was similar to the described above for the osmotic fragility but modified in order to include $1 \mathrm{mM}$ of $\mathrm{H}_{2} \mathrm{O}_{2}$. After exposure to the propolis extract, the RBC's were washed with a physiological saline solution and re-suspended in the physiological solution. Then, $1 \mathrm{mM}$ of $\mathrm{H}_{2} \mathrm{O}_{2}$ was added to the sample during $30 \mathrm{~min}$.

\subsubsection{Chelating activity}

The chelating activity of propolis extracts was measured as reported by Topçu et al. (2007). Each sample ( $1 \mathrm{~mL})$ was mixed with $3.7 \mathrm{~mL}$ of deionized water and then allowed to react with $0.1 \mathrm{~mL}$ of $\mathrm{FeCl}_{2}(2 \mathrm{mM})$ and $0.2 \mathrm{~mL}$ of ferrozine $(5 \mathrm{mM})$. The absorbance was measured spectrophotometrically at $562 \mathrm{~nm}$. The $\mathrm{Fe}^{2+}$ chelating activity of propolis was calculated using the following relation:

Chelating activity $(\%)=\left[\frac{1-(\text { sample absorption })_{562 \mathrm{~nm}}}{(\text { control absorption })_{562 \mathrm{~nm}}}\right] \times 100$

\subsection{Statistical analysis}

A statistical analysis was performed using the Statistical Package for Social Sciences v17. One-way analysis of variance (ANOVA) followed by Tukey's test was made to verify which variables are significantly different, with $\alpha=0.05$.

\section{Results and discussion}

\subsection{Polyphenolic composition of propolis}

The bioactive properties of propolis extracts are certainly related with its chemical composition. Several studies suggested that polyphenolic compounds are responsible for these properties (Moreno et al., 2000; Kumazawa et al., 2004; Banskota et al., 2001). In a previous work we showed that the two used propolis samples have different amounts of polyphenolic compounds (Moreira et al., 2008). The sample from Fundão showed a 
polyphenolic content of $151 \mathrm{mg} / \mathrm{g}$ while that from Bornes showed the double: $300 \mathrm{mg} / \mathrm{g}$.

The plant source is of crucial importance for the chemical composition and thus for the biological activity of propolis in a particular region. Indeed, sweet chestnut (Castanea sativa) is dominant in the region of Bornes while aspen (Populus tremula) is the main source of bee collected resin in Fundão region (Moreira et al., 2008). The higher polyphenolic content of Borne's propolis should be related with sweet chestnut trees. This can be relevant for the official acceptation of propolis in pharmaceutical industries and subsequently economic valorization of the product.

In order to identify which polyphenol compounds show higher content in the Bornes propolis sample, we study the polyphenol profiles of the two materials by LC-MS, under both, negative and positive ionization. Most components of the Northeast Portuguese propolis, namely the Bornes propolis, were identified in a previous work (Falcão et al., 2010). These include the typical phenolic acids and flavonoids found in propolis from temperate zones as well as novel compounds such as methylated and/or esterified or hydroxylated derivatives of common poplar flavonoids. We therefore focus on the main differences between the two tested propolis materials. Fig. 1 shows the LC-MS traces for the two samples under negative ionization polarity. The results are in agreement with the GAE determinations and indicated a general higher intensity of compounds with retention times between 30 and $60 \mathrm{~min}$ for Bornes propolis. Specifically, compounds with retention time

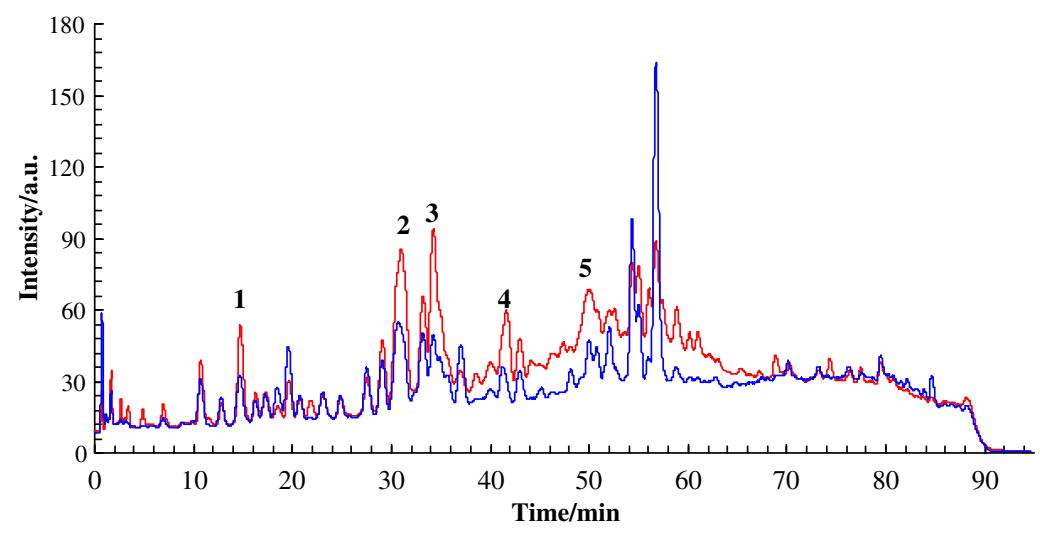

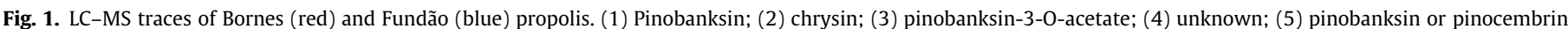

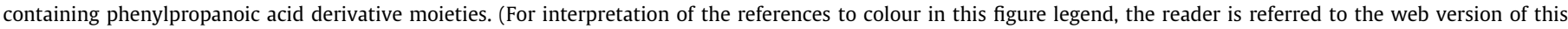
article.)

Table 1

Parameters (retention time, RT, $m / z$ of the parent ion, $[\mathrm{M}-\mathrm{H}]^{-}, m / z$ of the main fragments, $\mathrm{MS}^{2}$ ) of the main polyphenolic compounds showing higher signal intensities in Bornes propolis sample.

\begin{tabular}{|c|c|c|c|c|}
\hline Number & $\mathrm{RT}(\mathrm{min})$ & $m / z[\mathrm{M}-\mathrm{H}]^{-}$ & $\mathrm{MS}^{2}(\% \text { base peak })^{\mathrm{a}}$ & Compound \\
\hline 1 & 14.7 & 271 & 253 (100), 225 (20), 151 (10) & Pinobanksin \\
\hline 2 & 31.0 & 253 & 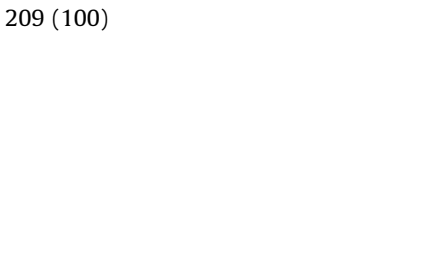 & $\begin{array}{l}\mathrm{OH}_{\mathrm{OH}} \\
\mathrm{O} \\
\\
\text { Chrysin }\end{array}$ \\
\hline 3 & 34.3 & 313 & 271 (21), $253(100)$ & Pinobanksin-3-O-acetate \\
\hline 4 & 41.6 & 295 & 251 (34), $211(43), 178$ (100), 134 (38) & Unknown \\
\hline 5 & 50.0 & $\begin{array}{l}417 \\
475\end{array}$ & $\begin{array}{l}281(63), 267(100) \\
433(29), 415(100)\end{array}$ & $\begin{array}{l}\text { Pinobanksin/pinocembrin containing phenylpropanoic } \\
\text { acid derivative moieties (Falcão et al., 2010) }\end{array}$ \\
\hline
\end{tabular}

a The numbers in parentheses denote the relative abundance of the respective fragment ion. 
14.7 (1), 31.0 (2), 34.3 (3), 41.6 (4) and 50.0 (5) min showed much higher intensity (Fig. 1). Based on the obtained fragmentation patterns of the detected negative and positive ions and on previous published LC-MS data (Gardana et al., 2007; Falcão et al., 2010), the peaks labelled in the LC-MS traces were assigned to pinobanksin (1), chrysin (2), pinobanksin-3-O-acetate (3) and pinobanksin/ pinocembrin containing a phenylpropanoic acid derivative moiety (5) (Table 1). Under negative ionization compound $\mathbf{4}$ shows a signal at $m / z=295\left([\mathrm{M}-\mathrm{H}]^{-}\right)$. MS/MS studies reveal the fragmentation of this ion into negative daughter ions with $m / z=251,211,178$ and 134 (see Table 1). This fragmentation pattern was not reported before for propolis materials and is compatible with an ester of ferulic acid. However, the definitive assignment of a structure to this compound requires its isolation, purification and detail NMR studies. The LC-MS results indicated that the bioactivity of propolis extracts, namely its effect on the red cell membrane, might be related with the polyphenolic contents. Moreover, the results also suggest that this activity is likely to be related with the specific polyphenols families, namely pinobanksin/pinocembrin containing phenylpropanoic acid derivative moieties.

\subsection{Laboratory diagnostic of hereditary spherocytosis}

In this work two adults were studied, one with the syndrome of HS splenectomised and one healthy used as control. Diagnosis of HS was made by clinical features, namely spherocytes on peripheral blood smear and abnormal osmotic fragility. The morphologic hallmark of HS is the presence of micropherocyte, which is caused by loss of membrane surface area. However, the definite test to detect HS is the osmotic fragility test (Rocha et al., 2009), which evaluates surface to volume ratio. Normal erythrocytes are characterized by a biconcave shape and show therefore higher surface to volume ratio than the spherocytes. This property increases the osmotic fragility of spherocytes, making them much more prone to haemolysis when suspended in hypotonic solutions. The amount of haemoglobin released is correlated with the osmotic fragility of the red cell's membranes. The microscopic observation of the peripheral blood of the HS individual showed the presence of microspherocytes that appear smaller, spherical, more intensely haemoglobinised and without a central pallor (Fig. 2). As expected, the osmotic fragility test for the HS patient gave a positive result. The haemolysis of RBCs started at $5.5 \mathrm{~g} / \mathrm{L}$ of $\mathrm{NaCl}$ (Fig. 3), while for healthy individuals it started at $5.0 \mathrm{~g} / \mathrm{L}$ of $\mathrm{NaCl}$ (Fig. 3). These results confirmed the clinical diagnosis of our patient.

\subsection{Propolis effect in the erythrocyte membrane integrity}

It is generally accepted that the HS is characterized by clinical, laboratorial and molecular heterogeneity (Favero et al., 2003; Granjo et al., 2003). There is also a possible oxidative damage of red blood cell membrane in HS similar to the one recorded in other haemolytic anaemia (Margetis et al., 2007). Indeed, the spherocytes were found to be more sensitive than normal erythrocytes to the action of oxidation inducing drugs. Margetis et al. (2007) reported increased amounts of haemoglobin in the electrophoretic analysis of RBC membranes of HS patients. The increase of haemoglobin values cause an increase of the free iron content, indicating that HS RBC's seem to be more prone to develop oxidative stress. Under oxidative stress cells respond accumulating ROS and the haemoglobin is exposed on the cytoplasmic surface. As a result of this process formation of microvesicles occurs and a decrease in the erythrocyte surface and loss of elasticity can be observed.

Flavonoids (including flavones, flavonols, flavanones and dihydroflavonols) and other phenolics (mainly substituted cinnamic acids and their esters) are the main active constituents of propolis and possess potent antioxidant activities (Moreno et al., 2000; Kumazawa et al., 2004; Banskota et al., 2001). However, most studies were performed with Brazilian and Eastern Europe propolis (Popova et al., 2004; Alencar et al., 2007). Studies conducted with Portuguese propolis are scarce and its antioxidant properties in RBC's were not investigated.

Chemical composition of propolis revealed that both propolis have the same main polyphenols, including the typical phenolic acids and flavonoids found in propolis from temperate zones (Falcão et al., 2010), being the main differences the content of each component. Moreover, Moreira et al. (2008), showed that both, Bornes and Fundão propolis had an effective DPPH radical scavenging and reducing activities.

The chromatograms shown in Fig. 4a are the single ion traces for the negative ion with $m / z=271\left([\mathrm{M}-\mathrm{H}]^{-}\right)$, obtained for both, the Bornes and the Fundão propolis. The comparison of these chromatograms clearly show that pinobanksin, which shows a $[\mathrm{M}-\mathrm{H}]^{-}$ion at 271 (see Table 1 ), is present in both materials but shows higher content in Bornes propolis. This supports the general idea that all propolis materials from temperate zones share the same main components, being the main differences their relative amounts. However, besides the typical phenolic acids and flavonoids found in propolis from temperate zones, several characteristic compounds have been reported only for Bornes propolis (Falcão et al., 2010). These include derivatives of pinocembrin/

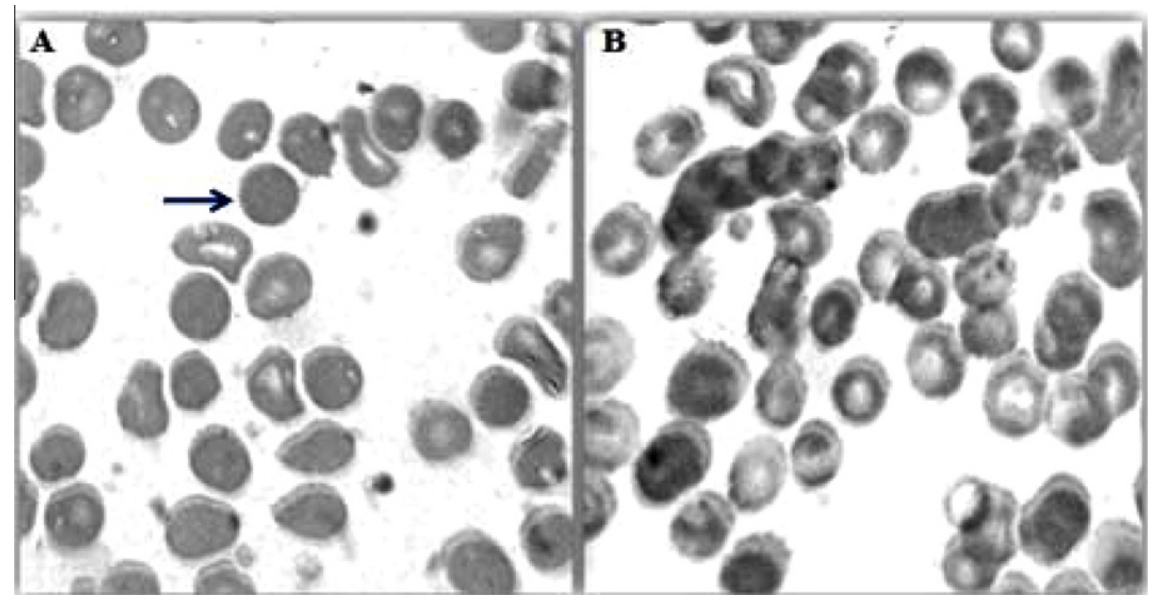

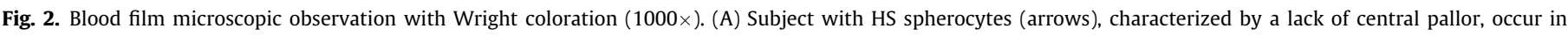
hereditary spherocytosis; (B) Control subject. $162 \times 87 \mathrm{~mm}(96 \times 96 \mathrm{DPI})$. 


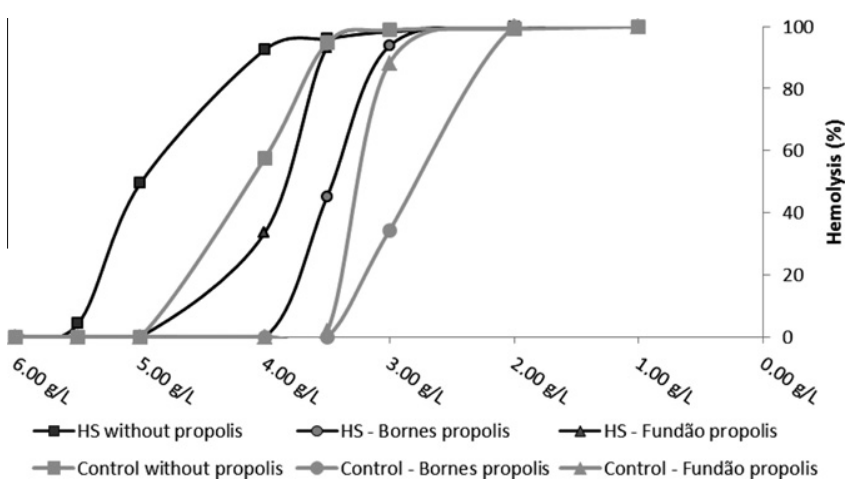

Fig. 3. Osmotic fragility curves of control subject and subject with HS, with and without exposure to propolis $120 \times 88 \mathrm{~mm}(96 \times 96 \mathrm{DPI})$.

pinobanksin, containing a phenylpropanoic acid derivative moieties in their structure. The chromatograms shown in Fig. $4 \mathrm{~b}$ are the single ion traces for the negative ion with $m / z=417\left([\mathrm{M}-\mathrm{H}]^{-}\right)$, obtained for both propolis materials. The chromatogram obtained for Bornes shows the presence of five major peaks, each of them corresponding to an isomer molecule and thus indicating the high complexity of propolis materials. It also shows that the compounds with a negative ion at $m / z 417$, as well as at $m / z=403,417,433$, 461 and 475 (Falcão et al., 2010), are highly specific of Bornes propolis. The aim of the present work was to determine if propolis could affect the red cell membrane integrity and if this action is related to polyphenolics compounds. In this study was used two propolis extracts with different polyphenolic contents. First, it was verified that the solvent (DMSO) did not affect the haemolysis. In all in vitro assays the same volume of propolis extract was added to the RBC's samples (HS and healthy individuals. The results of osmotic fragility tests, shown that the erythrocyte membrane fragility of both individuals was affected by propolis extract, leading to a curve dislocation to the right (Fig. 3). In the control individual the haemolysis without propolis addition started at $5 \mathrm{~g} / \mathrm{L} \mathrm{NaCl}$, while with the propolis extracts it started at $3.5 \mathrm{~g} / \mathrm{L}$. However, the haemolysis kinetic, was affected in a different way by the two propolis extracts used. At $3.0 \mathrm{~g} / \mathrm{L}$ of $\mathrm{NaCl} 80 \%$ of haemolysis was verified when Fundão propolis is added while only $30 \%$ was observed when using Bornes propolis, suggesting that Bornes propolis protected more efficiently the membrane integrity. In the case of HS patient, the effect of propolis was more pronounced (Fig. 3). When Bornes propolis was added to RBC's the haemolysis started only at $4.0 \mathrm{~g} / \mathrm{L} \mathrm{NaCl}$ while with Fundão propolis it started at $5.0 \mathrm{~g} / \mathrm{L} \mathrm{NaCl}$. These results clearly indicate that propolis decreased the osmotic fragility of erythrocytes in vitro.

These results are in agreement with the GAE determinations and with the LC-MS data, which showed a higher polyphenol content for Bornes propolis. The results therefore suggest that the bioactivity of propolis extracts, namely its effect on the red cell membrane, might be related with the polyphenolic contents. Moreover, this activity is likely to be related with the specific polyphenols families, namely pinobanksin/pinocembrin derivatives.

\section{4. $\mathrm{H}_{2} \mathrm{O}_{2}$ and propolis effect on RBCs membrane integrity}

Zhu et al. (2001) observed that lipids and protein oxidation in cell membrane induce haemolysis.

We study the influence of $\mathrm{H}_{2} \mathrm{O}_{2}$ in erythrocytes haemolysis of healthy and HS subjects and also investigated the role of propolis in RBCs membrane integrity under oxidative stress. Unpublished data from our laboratory show that hydrogen peroxide at $2.65 \mathrm{M}$ induce the oxidation of haemoglobin to methaemoglobin (green colour solution) and that this effect was abolished by propolis.

RBCs of both subjects were submitted to oxidative stress with $1 \mathrm{mM}$ of $\mathrm{H}_{2} \mathrm{O}_{2}$ during $30 \mathrm{~min}$. The erythrocyte membrane integrity
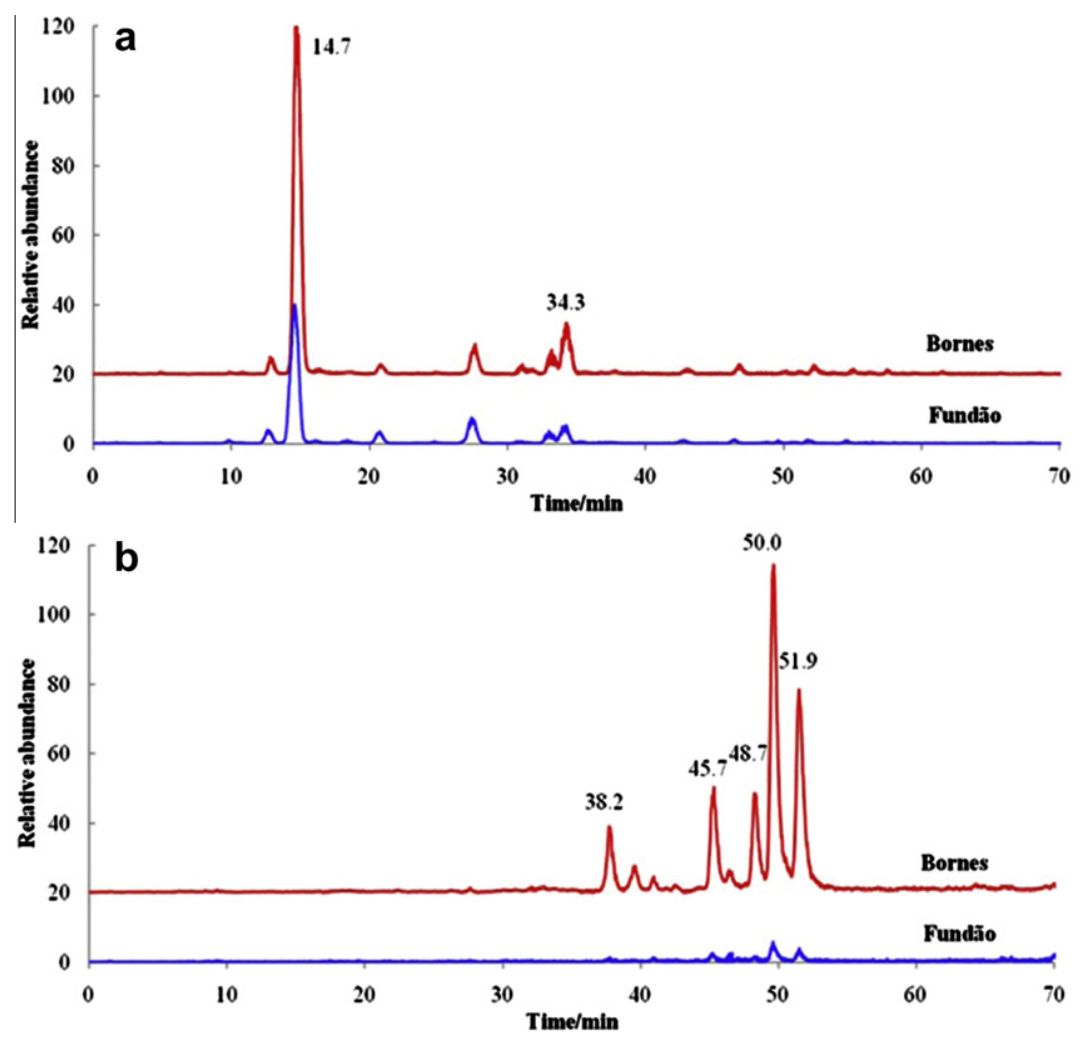

Fig. 4. Single ion LC-MS traces of Bornes (red) and Fundão (blue) propolis, obtained under negative ionization for $m / z=271(\mathbf{a}))$ and $m / z=417(\mathbf{b})$ ). 


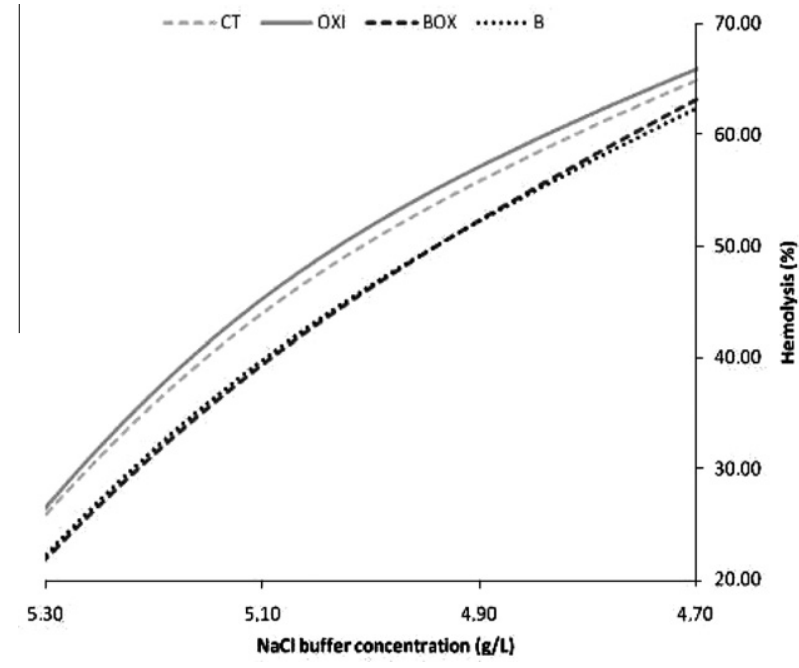

Fig. 5. Oxidation effect on osmotic fragility with and without propolis on hereditary spherocytosis subject (CT - control; OXI - with hydrogen peroxide; BOX - with hydrogen peroxide and propolis; and (B) with propolis). $127 \times 115 \mathrm{~mm}(96 \times 96$ DPI).

of the control subject was not affected by this $\mathrm{H}_{2} \mathrm{O}_{2}$ concentration (Fig. 5). This result is in agreement with the studies by El-Missiry and Abou-Seif (2000) that reported oxidative haemolysis by $m$-CPBA only after RBCs photo-sensibilization to increase the oxidative stress. In the HS patient the haemolysis also started at same $\mathrm{NaCl}$ concentrations, but was observed a slight increase of haemolysis, since the OFT curve shift to the left. Moreover, the cells pre-treated with Bornes propolis have the same behaviour of unstressed cells treated with propolis (Fig. 5). The statistical analysis revealed significantly differences in haemolysis between the RBC treated with propolis and propolis/oxidant $(p=0112)$, suggesting that the oxidant effect in the $\mathrm{RBC}$, caused by $\mathrm{H}_{2} \mathrm{O}_{2}$, was blunted by propolis.

This study shows that in vitro, the osmotic fragility may be increased by oxidative stress conditions in RBCs of HS patient and the protection of membrane integrity by propolis can due to its antioxidant properties.

The fact that, haemolysis level of normal RBCs has not been affected by $\mathrm{H}_{2} \mathrm{O}_{2}$, can be related with an efficient antioxidant defense system that prevents oxidative damage (Lii and Hung, 1997; Rossi et al., 2001), or because the RBC's incubation's time (30 min) with the $\mathrm{NaCl}$ solution was low, when comparing with the $8 \mathrm{~h}$ used by Zhu et al., 2001.

Further studies, such a measurement in vitro of the effect of propolis in the oxidation level of membrane proteins and lipids under oxidative stress conditions are required.

\subsection{Chelating effect on ferrous ions}

The higher haemoglobin content for HS patient RBC's (Margetis et al., 2007) increased iron ions level. Ferrali et al. (1989, 1990, 1993) showed that iron is released in a free (desferrioxamine (DFO) chelatable) form when mouse erythrocytes are incubated with a number of oxidizing agents. Iron is released from haemoglobin and the release is accompanied by methaemoglobin formation. If the erythrocytes are severely depleted of glutathione (GSH), the release of iron is followed by peroxidation of membrane lipids and haemolysis. Transition metal ions such as $\mathrm{Fe}^{2+}$, are able to move free electrons and this way they allow the formation and propagation of many radical reactions, even if they start with relatively non-reactive radicals (Aboul-Enein et al., 2003). Chelating activity

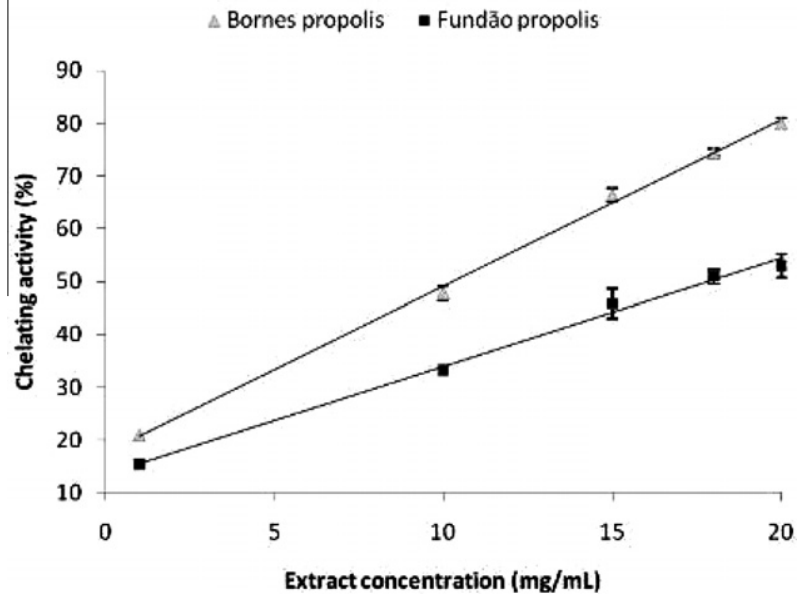

Fig. 6. Chelating activity of propolis extracts: Bornes and Fundão. $120 \times 91 \mathrm{~mm}$ $(96 \times 96 \mathrm{DPI})$

tests were performed in order to study the propolis effect on availability of transition metal ions involved on ROS production. The chelating effect of propolis was evaluated by the method of Topçu et al. (2007). Ferrozine can form complexes with $\mathrm{Fe}^{2+}$, originating a violet colour.

Propolis quenches the formation of the ferrozine- $\mathrm{Fe}^{2+}$ complex. The $\mathrm{IC}_{50}$ for Bornes' propolis was $10.3 \mathrm{mg} / \mathrm{mL}$ while for Fundão was $17.8 \mathrm{mg} / \mathrm{mL}$ (Fig. 6). These IC50 values are in agreement with the polyphenol contents as suggested by LC-MS data.

The protective effect of propolis towards the erythrocyte membranes can be attributed to their iron chelation capacities, since they can extract iron ions and hinder radical reactions. Ferrali et al. (1997) show also, that flavonoid quercetin prevent the oxidative damage induced in the erythrocytes and this protection is due to intracellular chelation of iron. Moreover, the phenolic and flavonoids compounds, can scavenge free hydroxyl and peroxyl radicals and protect the membranes. The effect of propolis is more pronounced in erythrocytes from HS patient because these cells have increased amounts of haemoglobin and iron ions and consequently they are under higher oxidative stress.

Another possibility is that propolis, namely phenolics compounds stabilize the erythrocyte membrane by interaction with membrane phospholipids. It has been documented that the interaction between some flavonoids and the lipid bilayer. Some can binding at the lipid-water interface, or are distributed in the hydrophobic core of the membrane, or interacted with the membrane's outer phospholipid monolayer (Suwalsky et al., 2008; Oteiza et al., 2005; Verstraeten et al., 2003; Bombardelli et al., 1989).

\section{Conclusion}

This study intended to evaluate the propolis effect on human erythrocyte membrane.

LC-MS analysis of the used propolis samples showed the typical polyphenol compounds found in propolis from temperate zones. Propolis from Bornes showed higher polyphenol contents, namely of pinobanksin, chrysin, pinobanksin-3-O-acetate and pinobanksin/pinocembrin containing phenylpropanoic acid derivative moieties.

Propolis decreased the osmotic fragility of erythrocytes, nevertheless its effect was more pronounced in RBCs from HS Patient. Moreover, the Bornes propolis extract was more efficient. This difference can be related with the phenolics content. In fact, our research group has verified in other studies, that Bornes propolis has twice the phenolic compounds of Fundão propolis. 
The osmotic fragility may be increased by oxidative stress conditions in RBCs of HS patient and the propolis blunted this effect.

Bornes' propolis showed a chelating activity twice higher that Fundão propolis.

All data indicated that the propolis bioactivity in RBC membrane integrity is due to phenolic compounds.

Given the potential impact of these preliminary findings, we will develop studies to identify the main compounds involved in the protection of the red cells, as well as the identification of molecular targets of erythrocyte membrane. Simultaneously, we intend to increase sample size and studied the effects of diets containing different Propolis (or propolis compounds) on erythrocyte membrane integrity in vivo.

\section{Ethics}

We have followed all the standards that govern human trials, and obtain informed consent.

\section{Acknowledgement}

Part of this study was supported by Centro de Investigação de Montanha, Bragança, Portugal.

\section{References}

Aboul-Enein, A., El-Baz, F., El-Baroty, G., Youssef, A., Abd El-Baky, H., 2003. Antioxidant activity of algal extracts on lipid peroxidation. Journal of Medical Sciences 3, 87-98.

Alencar, S., Oldoni, T., Castro, M., Cabral, I., Costa-Neto, C., Cury, J., Rosalen, P., Ikegaki, M., 2007. Chemical composition and biological activity of a new type of Brazilian propolis. Red propolis. Journal of Ethnopharmacology 113, 278-283.

Amoros, M., Lurton, E., Boustie, J., Girre, L., Sauvager, F., Cormier, M., 1994. Comparison of the anti-herpes simplex virus activities of propolis and 3methylbut-2-enyl caffeate. Journal of Natural Products 64, 235-240.

Bankova, V., 2005. Recent trends and important developments in Propolis Research. Evidence Based and Complementary Alternative Medicine 2, 29-32.

Bankova, V., De Castro, S., Marcucci, M., 2000. Propolis: recent advances in chemistry and plant origin. Apidologie 31, 3-15.

Banskota, A., Tezuka, Y., Kadota, S., 2001. Recent progress in pharmacological research of propolis. Phytotherapy Research 15, 561-571.

Bombardelli, E., Curri, S., Della, L., Del, N., Tubaro, A., Gariboldi, P., 1989. Complex between phospholipids and vegetable derivatives of biological interest. Fitoterapia LX (Suppl. 1), 1-9.

Búfalo, M., Candeias, J., Sforcin, J., 2009. In vitro cytotoxic effect of Brazilian green propolis on human laryngeal epidermoid carcinoma (Hep-2) cells. Evidence Based and Complementary Alternative Medicine 6, 483-487.

Daugsch, A., Moraes, C., Fort, P., Park, Y., 2008. Brazilian red propolis-chemical composition and botanical origin. Evidence Based and Complementary Alternative Medicine 5, 435-441.

El-Missiry, M., Abou-Seif, M., 2000. Photosensitization induced reactive oxygen species and oxidative damage in human erythrocytes. Cancer Letters 158, 155163.

Falcão, S.I., Vilas-Boas, M., Estevinho, L.M., Barros, C., Domingues, M.R.M., Cardoso, S.M., 2010. Phenolic characterization of Northeast Portuguese propolis: usual and unusual compounds. Analytical and Bioanalytical Chemistry 396, 887-897.

Favero, P., Leonart, M., Nascimento, A., 2003. Electroforese de proteínas de membrana eritrocitária no diagnóstico de doença haemolítica por defeito de membrana. Revista Brasileira de Análises Clínica 35, 45-47.

Ferrali, M., Ciccoli, L., Comporti, M., 1989. Allyl alcohol-induced haemolysis and its relation to iron release and lipid peroxidation. Biochemical Pharmacology 38, 1819-1825.

Ferrali, M., Ciccoli, L., Signorini, C., Comporti, M., 1990. Iron release and erythrocyte damage in allyl alcohol intoxication in mice. Biochemical Pharmacology 40, 1485-1490.

Ferrali, M., Signorini, C., Caciotti, B., Sugherini, L., Ciccoli, L., Giachetti, D., Comporti, M., 1997. Protection against oxidative damage of erythrocyte membrane by the flavonoid quercetin and its relation to iron chelating activity. FEBS Letters 416, 123-129.

Ferrali, M., Signorini, C., Ciccoli, L., Comporti, M., 1993. Iron released from an erythrocyte lysate by oxidative stress is diffusible and in redox active form. FEBS Letters 319, 40-44.
Gardana, C., Scaglianti, M., Pietta, P., Simonetti, P., 2007. Analysis of the polyphenolic fraction of propolis from different sources by liquid chromatography tandem mass spectrometry. Journal of Pharmaceutical and Biomedical Analysis 45, 390-399.

Granjo, E., Manata, P., Torres, N., Rodrigues, L., Ferreira, F., Bauerle, R. 2003. Esferocitose Hereditária-prevalência dos défices proteícos da membrana do eritrócito. Acta Médica Portuguesa 16, 65-69.

Kumazawa, S., Hamasaka, T., Nakayama, T., 2004. Antioxidant activity of propolis of various geographic origins. Food Chemistry 84 (3), 329-339.

Lii, C., Hung, C., 1997. Protein thiol modifications of human red blood cells treated with t-butyl hydroperoxide. Biochimica et Biophysica Acta 1336 (2), 147-156.

Marcucci, M., 1995. Propolis: chemical composition, biological properties and therapeutic activity. Apidologie 26, 83-99.

Marcucci, M., Bankova, V., 1999. Chemical composition, plant origin and biological activity of Brazilian propolis. Current Topics in Phytochemistry 2, 115-123.

Margetis, P., Antonelou, M., Karababa, F., Loutradi, A., Margaritis, L., Papassideri, I., 2007. Physiologically important secondary modifications of red cell membrane in hereditary spherocytosis-evidence for in vivo oxidation and lipid rafts protein variations. Blood Cells, Molecules, and Diseases 38, 210-220.

Moreira, L., Dias, L., Pereira, J., Estevinho, L., 2008. Antioxidant properties, total phenols and polinic analysis of propolis samples from Portugal. Food and Chemical Toxicology 46, 3482-3485.

Moreno, M.I., Isla, M.I., Sampietro, A.R., Vattuone, M.A., 2000. Comparison of the free radical-scavenging activity of propolis from several regions of Argentina. Journal of Ethnopharmacology 71, 109-114.

Moura, S., Negri, G., Satatino, A., Lima, L., Dourado, L., Mendes, J., 2009. Aqueous extract of Brazilian Green Propolis: primary components, evaluation of inflammation and wound healing by using subcutaneous implanted sponges. Evidence Based and Complementary Alternative Medicine.

Orcutt, R., Thurmond, T., Ferslew, K., 1995. Mathematical modeling of the osmotic fragility of rabbit red blood cells. Journal of Pharmacological and Toxicological Methods 34, 169-174.

Oteiza, P., Erlejman, A., Verstraeten, S., Keen, C., Fraga, S., 2005. Flavonoidmembrane interactions: a protective role of flavonoids at the membrane surface? Clinical and Developmental Immunology 12 (1), 19-25.

Park, Y., Alencar, S., Aguiar, C., 2002. Botanical origin and chemical composition of Brazilian propolis. Journal of Agriculture and Food Chemistry 50, 2502-2506.

Popova, M., Bankova, V., Butovska, D., Petkov, V., Nikolova-Damyanova, B., Sabatini, A., Marcazzan, G., Bogdanov, S., 2004. Validated methods for the quantification of biologically active constituents of poplar-type propolis. Phytochemical Analysis 15, 235-240.

Rocha, S., Costa, E., Coimbra, S., Nascimento, H., Catarino, C., Rocha-Pereira, P., 2009 Linkage of cytosolic peroxiredoxin 2 to erythrocyte membrane imposed by hydrogen peroxide-induced oxidative stress. Blood Cells, Molecules, and Diseases 43, 68-73.

Rossi, R., Milzani, A., Dalle-Donne, I., Giannerini, F., Giustarini, D., Lusini, L., Colombo, R., Di Simplicio, P., 2001. Different metabolizing ability of thiol reactants in human and rat blood: biochemical and pharmacological implications. The Journal of Biological Chemistry 276 (10), 7004-7010.

Salatino, A., Teixeira, E., Negri, G., Message, D., 2005. Origin and chemical variation of Brazilian Propolis. Evidence Based and Complementary Alternative Medicine 2, 33-38.

Salomão, K., Pereira, P., Campos, L., Borba, C., Cabello, P., Marcucci, M., 2008. Brazilian Propolis: correlation between chemical composition and antimicrobial activity. Evidence Based and Complementary Alternative Medicine 5, 317-324.

Satchwell, T., Shoemark, D., Sessions, R., Toye, A., 2009. Protein 4.2: a complex linker. Blood Cells, Molecules, and Diseases 42, 201-210.

Suwalsky, M., Vargas, P., Avello, M., Villena, F., Sotomayor, C., 2008. Human erythrocytes are affected in vitro by flavonoids of Aristotelia chilensis (Maqui) leaves. International Journal of Pharmaceutics 363 (1-2), 85-90.

Szliszka, E., Czuba, Z., Bronikowska, J., Mertas, A., Paradysz, A., Krol, W., 2009 Ethanolic extract of Propolis augments TRAIL - Induced apoptotic Death in prostate cancer cells. Evidence Based and Complementary Alternative Medicine doi:10.1093/ecam/nep180.

Topçu, G., Ertaş, A., Kolak, U., Öztürk, M., Ulubelen, A., 2007. Antioxidant activity tests on novel triterpenoids from Salvia macrochlamys. Arkivoc 7, 195-208.

Tracy, E., Rice, H., 2008. Partial splenectomy for hereditary spherocytosis. Pediatric Clinics of North America - Hematology 55, 503-519.

Verstraeten, S., Keen, C., Schmitz, H., Fraga, C., Oteiza, P., 2003. Flavan-3-ols and procyanidins protect liposomes against lipid oxidation and disruption of the bilayer structure. Free Radicals Biology Medicine 34, 84-92.

Wagner, G., Chiu, D., Yee, M., Lubin, B., 1986. Red cell vesiculation - a common membrane physiological event. Journal of Laboratory and Clinical Medicine 108, 315-324.

Zhu, C., Agar, N., Jones, G., 2001. Oxidative insult to human red blood cells induced by free radical initiator AAPH and its inhibition by a commercial antioxidant mixture. Life Sciences 69 (1), 75-86. 